The University of San Francisco

USF Scholarship: a digital repository @ Gleeson Library |

Geschke Center

$1-2015$

\title{
A Compensating Differential Approach to Valuing the Social Benefit of Minor League Baseball
}

Nola Agha

University of San Francisco, nagha@usfca.edu

Dennis Coates

University of Maryland - Baltimore County

Follow this and additional works at: http://repository.usfca.edu/sm

Part of the Sports Management Commons

\section{Recommended Citation}

Agha, N. \& Coates, D. (2015). A compensating differential approach to valuing the social benefit of Minor League Baseball. Contemporary Economic Policy, 33(2), 285-299. DOI: 10.1111/coep.12080

This Article is brought to you for free and open access by the College of Arts and Sciences at USF Scholarship: a digital repository @ Gleeson Library | Geschke Center. It has been accepted for inclusion in Sport Management by an authorized administrator of USF Scholarship: a digital repository @

Gleeson Library | Geschke Center. For more information, please contact repository@usfca.edu. 


\title{
A COMPENSATING DIFFERENTIAL APPROACH TO VALUING THE SOCIAL BENEFIT OF MINOR LEAGUE BASEBALL
}

\begin{abstract}
This research utilizes a compensating differential framework to measure the social benefits of minor league baseball teams. Consistent with findings at the major league level, individual housing observations from 138 metropolitan areas between 1993 and 2005 show that affiliated teams are associated with a significant 6 to $8 \%$ increase in rents in mid-sized markets ranging from 0.4 to 1.4 million people. On the other hand, independent teams and stadiums are associated with insignificant effects on rents. The positive effect of affiliated minor league teams suggests they are a valuable urban amenity that can contribute to local quality of life. (JEL $\mathrm{H} 23$, H41, H71, R50, and L83)
\end{abstract}

Keywords: compensating differentials, public good, hedonic model, minor league baseball, economic impact

Please cite this paper as:

Agha, N. \& Coates, D. (2015). A compensating differential approach to valuing the social benefit of Minor League Baseball. Contemporary Economic Policy, 33(2), 285-299.

DOI: $10.1111 /$ coep. 12080

For access to the full article, please visit

http://onlinelibrary.wiley.com/doi/10.1111/coep.12080/abstract 


\section{INTRODUCTION}

Spectator sports are an important part of our national culture in no small part due to the positive "community pride" effect from having a team (Johnson \& Sack, 1996; Swindell \& Rosentraub, 1998). Indeed Noll and Zimbalist (1997, p. 56) go so far as to assert, "The cultural importance of major league team sports in American society most assuredly exceeds its economic significance as a business."

In an economic framework this cultural importance derives from a professional team's positive consumption externalities that manifest themselves through civic pride, the "big league" status of a city, or the simple happiness when a fan's favorite team wins. These intangible benefits have value.

Although a mention of professional sports immediately brings to mind major league baseball, football, hockey, and basketball, there is a professional sport played in over 200 North American cities every year that boasts higher total attendance than the National Basketball Association (NBA), National Football League (NFL), or National Hockey League (NHL) (see Figure 1). Minor league baseball has existed since 1901 and is played in more communities than all of the major league team sports combined.

\section{<insert Figure 1>}

Hundreds of minor league baseball teams have played in North American cities for over a hundred years. Further, similar to major league sports, cities compete for the opportunity to spend tens of millions of public dollars on new minor league stadiums. Given these facts, it might be reasonable to suspect that minor league baseball has a non-pecuniary value to its host community, yet little is known about this value. There are two opposing views. The first views minor league baseball as a small, insignificant game played in front of small crowds in small 
venues in relatively small cities. It lacks national television exposure, overflow crowds, and super stars with super salaries. Without the cachet of major league sports, it has little ability to generate intangible benefits for a local community.

The second view focuses on the relative worth of a team as opposed to its absolute size (Johnson, 1995; Kraus, 2003; Rosentraub \& Swindell, 1991). A local sports team is viewed as a unique geographic and cultural attribute that outsiders associate with a city. If the team's positive consumption externalities are manifested through the generation of local pride in place and pride in team then these intangible benefits are valuable.

Both views incorporate the size of the city in the argument either directly or in the calculation of relative worth. The idea of relative effects is not new to sports research. Coates and Depken (2011) state, "for Waco, Lubbock, or other middle or small sized cities, a regular season college football game may be a mega-event" (p. 601). Because minor league baseball is extremely heterogeneous in population (in the most extreme case, teams in the same classification play in cities that range in population from 48,247 to $18,782,715$ ), an important contribution is the analysis of this effect in different sized cities. Measurement of these intangible benefits is important because minor league baseball teams seek subsidies from state and local governments for construction of new stadiums. While these subsidies are generally far smaller than those sought by major league franchises, they can be substantial, especially for the smaller communities that host lower level minor league teams. For example, since 2002 the average cost of a new ballpark at the highest level of the minor leagues (AAA) is $\$ 53$ million, and at the lowest level of minor league baseball (rookie league) a new stadium costs $\$ 8.5$ million. Of the eleven AAA and rookie stadiums built in this time period, all except one were $100 \%$ publicly financed. If the cost of the stadium was distributed equally to the residents of 
these metro areas, the per capita cost would be $\$ 53.16$ in AAA markets and $\$ 71.42$ in rookie markets. By comparison, the per capita cost of Major League Baseball (MLB) stadiums built since 2002 was $\$ 77.91$. Thus, minor league cities throughout the U.S. face a problem identical to that of major league cities - determining the best use of public funds based on the tangible and intangible effects of minor league teams and stadiums. While the tangible benefits of minor league teams have been estimated (Agha, 2013), the intangible effects have not.

The purpose of this research is to measure the intangible benefits provided by minor league baseball teams and to quantify variations in those effects in different sized cities. With hundreds of minor league baseball communities pressured to fund stadiums as a type of urban renewal, the existence and value of a minor league baseball public good has implications for a wide range of American cities.

Our method is to estimate hedonic rent equations (Rosen, 1974) to determine the extent to which a team, as a valuable local amenity, adds to local quality of life inducing greater demand for living space in the community resulting in higher rents. This theory presupposes no direct link between a sports team or facility and local economic activity. Rather, it views a professional sports team as a local amenity similar to good weather or a good opera. If individuals with a strong preference for access to professional sports migrate to an area in sufficient numbers, or don't emigrate from the area, to drive up rents there has been a “compensating differential" (Coates \& Humphreys, 2003). Instead of being viewed as a drain on a local economy, a professional sports team is seen as a positive amenity that makes an area more desirable. The degree to which this amenity is capitalized into rents and wages can then be measured through market-generated data, although it is indirectly measuring the value of the amenity (Coates, 2007). 
This research uses the hedonic rent/compensating differential framework to test for the presence and extent of the social benefit of a minor league baseball franchise to its local community. Using data on individual housing units from 138 Primary Metropolitan Statistical Areas (PMSAs) from the American Housing Survey (AHS) conducted by the Bureau of the Census, the results indicate that affiliated minor league teams in mid-sized markets ranging in size from 0.4 to 1.4 million people are associated with a $6-8 \%(\mathrm{p}<0.05)$ increase in rents. This effect is not limited to growing cities or those that gain a franchise. Independent teams are associated with no change in rents regardless of the size of the market. The positive effect of affiliated teams in some markets is consistent with the gains found in major league sports.

\section{BACKGROUND AND LITERATURE}

Thus far, the terms positive externality, public good, social benefit, and intangible benefit have been used interchangeably. In a sporting context this is for good reason.

There is a clear consensus that teams generate positive consumption externalities. For example, the mere presence of a team confers a "big league" status to a city (Okner, 1974; Rappaport \& Wilkerson, 2001; Zimmerman, 1997), it creates a topic of conversation around the proverbial water cooler (Siegfried \& Zimbalist, 2000; Zimmerman, 1997), it enhances the image of a city which can validate its worth and be a form of free advertising (Siegfried \& Zimbalist, 2000), and most generally it results in happiness (Rappaport \& Wilkerson, 2001). All of these benefits accrue to individuals who may not consume the actual sport product through live attendance, broadcasts, or purchases of licensed merchandise. Similarly, teams generate negative externalities such as traffic, noise, pollution, and interruption of regularly scheduled television programming that may decrease the local quality of life even for those who do not 
consume the sport product (Rappaport \& Wilkerson, 2001). The loss of a team can also lead to decreases in happiness, morale, image, and pride (Foster \& Hyatt, 2007).

All of these non-pecuniary benefits, and the costs, may disappear or never materialize without financial support from the local government. The important public policy question is, therefore, if the public goods nature of a team generates sufficient net public benefits, both pecuniary and non-pecuniary, to justify large government expenditures on a new stadium. The largest challenge in this line of argument is measuring the value of an inherently non-pecuniary construct (Coates, 2007). Three primary methods have been employed to measure these benefits — surveys, contingent valuation methods, and hedonic/compensating differentials—and all three have found positive effects at the major league level.

Using a phone survey, Rosentraub et al. (2008) estimated the intangible benefits of the NFL Indianapolis Colts at $\$ 83.9$ million. Similarly, the contingent valuation method, used extensively in the resource economics literature to value the public good of natural spaces, also relies on surveys to estimate aggregate willingness to pay. An ex ante study of a proposed college basketball arena and a proposed minor league baseball stadium showed that neither would generate enough value from public goods to justify public expenditures (Johnson \& Whitehead, 2000). Likewise, the value of the Pittsburgh Penguins did not exceed the cost of a proposed new arena (Johnson et al., 2001) and the public good of the Jacksonville Jaguars was less than the annual public expenditure on their stadium (Johnson et al., 2007).

Compensating differentials are measured through the hedonic price method, either estimating wage or rent differentials. Court (1939) first used the term "hedonic" in relation to the prices and demand for attributes which together form a heterogeneous commodity. Griliches (1961, 1971), Rosen (1974), and Roback (1982) are the more current sources of this theory and 
technique. Hamilton and Kahn (1997) proposed this theory may apply to professional sports teams but it was not until 2004 that Carlino and Coulson applied hedonic methods to the sporting context in an effort to measure the social benefit of an NFL franchise. The authors conducted a large number of analyses (pooled OLS, robust estimator, robust estimator with random effect, robust estimator with fixed-effects, and a state-time interaction) at three different levels of geographical aggregation, and only found a positive and statistically significant rent effect (of $8 \%$ ) in a central city sample with cluster corrected standard errors.

Coates and Gearhart (2008) used the same approach to investigate the effects of NASCAR tracks and races on local housing markets. Instead of limiting the effect of the sports variable to the difference between two time periods as in Carlino and Coulson (2004), the data sample from the AHS was expanded to include all of the odd numbered years between 1993 and 2005. Similarly, Coates and Matheson (2011) use AHS data from 1993 to 2005 and find that hosting mega-events has little consistent effect on rental prices.

Additional hedonic models address the impact on property values rather than on rents. Dehring et al. (2007) published a paper on the changes in residential property values in Dallas due to stadium announcements using a hedonic housing price equation while $\mathrm{Tu}$ (2006) investigated price differentials between housing units in different proximities to FedEx Field. Similarly, Ahlfeldt and Maennig (2010) and Feng and Humphreys (2012) found a gradient of housing price changes around stadiums in Berlin and the U.S., respectively.

The use of the hedonic, compensating differential approach to measuring the amenity or public goods value of sports has its pitfalls. Chief among these concerns is the correlation of the sport variables with the regression error term, possibly because of reverse causation. Other issues include the model specification, and collinearity between team presence and city size. There are 
also questions about the quality of the AHS data that we use. The ways in which this research addresses these issues are discussed below. But first we provide background information on Minor League Baseball.

\section{MINOR LEAGUE BASEBALL}

Minor league teams can be formally affiliated with major league franchises, or they can be independent. Minor League Baseball is a system of hierarchical leagues whose teams are affiliated with major league teams, where players of increasing skills move up until they reach the major leagues. The lowest classifications are rookie leagues followed by A, AA, and AAA. Affiliated minor league teams reap several distinct benefits from their formal working relationship with a MLB franchise. This includes association with the major league team name, brand, and logo; higher quality players that may one day move up to the big leagues; additional national media coverage when a major league player moves down into the minors; and a formal system of payment whereby the major league club pays the salaries of minor league players and coaches.

Independent minor league teams have no contractual relationships with MLB franchises, generally do not employ players that are seeking to play for MLB, do not receive any assistance from MLB clubs, and are financially responsible for all of their expenses. Because of this, independent teams and leagues are more unstable than affiliated classifications with an average tenure in a city that is less than $30 \%$ that of affiliated team tenure (see Table 1). In addition to more frequent moves, minor league baseball is different from MLB in a very important way. Whereas there are only four markets with two MLB teams, it is relatively common to have multiple affiliated or independent minor league teams, especially in metropolitan areas like 
Chicago, Dallas, and Los Angeles. For example, in 1995 the Riverside-San Bernardino PMSA hosted five affiliated teams and one independent team. To capture the partial effects of each type of team we employ a method used in all similar major league (e.g. Coates \& Humphreys, 2003) and minor league research (e.g. Agha, 2013) that counts the number of each type of team in each city.

<insert Table 1>

Minor league research has shown that teams in different classifications have differential impacts on a variety of dependent variables (Agha, 2013; Gitter \& Rhoads, 2010; Roy 2008; Winfree, 2005). While it would be preferable to disaggregate each level of affiliated minor league baseball (AAA-rookie) it is not possible due to sample size restrictions; there are simply not enough observations for each classification in each different population range ${ }^{1}$. We acknowledge the possibility that aggregating all affiliated teams may obscure differences between classifications, but this is preferable to using a sample size of only one team to generalize to the other teams in the same classification. In light of this, the analysis uses variables that count affiliated minor league teams and independent minor league teams in each city.

As explained in the introduction, there are two prevailing views on the social benefit of minor league teams which both rely on the size of the city. The idea of relative effects is not new to sports research (e.g. Coates \& Depken, 2011). Similarly, Seaman (2004), Matheson (2006), and Agha and Rascher (in press) suggest that smaller cities may be more likely to experience positive economic impacts from sport events and teams. As can be seen from Table 1, in the most extreme case, teams in the same classification can have a population range of more

\footnotetext{
${ }^{1}$ Moreover, unreported analysis of individual minor league classifications indicated results were sensitive to influential PMSAs. These results are available upon request.
} 
than 18 million. Thus, the models further delineate cities by population quartiles to isolate differential impacts in cities of vastly different sizes.

\section{MODEL SPECIFICATION AND ESTIMATION ISSUES}

In order to make comparisons between minor league results and existing major league research, the model employed here is adapted from both Carlino and Coulson (2004) and Coates and Gearhart (2008). To test the hypothesis that the presence of a minor league baseball team is a local amenity that leads to an increase in rent levels, a regression equation is used to predict the $\log$ of monthly rent paid by household $i$ in city $j$ at time $t$. The number of households varies by jurisdiction $j$ and time period $t$ and there are $j=1, \ldots, J$ jurisdictions and $t=1, \ldots, T$ time periods. Specifically,

where:

$$
\ln R_{i j t}=\beta_{1} H_{i j t}+\beta_{2} S_{j t}+\beta_{3} Z_{j t}+\sum_{j=1}^{J} \beta_{4 j} C_{j}+\sum_{j=1}^{J} \beta_{5 j} T_{j}+u_{i j t}
$$

$\ln R_{i j t}$ is the natural log of monthly rent paid by household $i$ in PMSA $j$ at time $t$

$\beta_{1}$ is a vector of parameters to be estimated for implicit prices of housing attributes $H_{i j t}$ is a vector of housing unit attributes for household $i$ in PMSA $j$ at time $t$ $\beta_{2}$ is a vector of parameters to be estimated for implicit prices of sporting characteristics $S_{j t}$ is a vector of sporting variables that varies by PMSA $j$ at time $t$

$\beta_{3}$ is a vector of parameters to be estimated for implicit prices of city characteristics $Z_{j t}$ is a vector of city economic and social characteristics that varies by PMSA $j$ at time $t$ $\beta_{4 j}$ are $J$ PMSA $_{j}$-specific intercepts to be estimated

$C_{j}$ are $\mathrm{PMSA}_{j}$-specific dummy variables

$\beta_{5 j}$ are $J \mathrm{PMSA}_{j}$-specific time trend parameters to be estimated

$T_{j}$ are $\mathrm{PMSA}_{j}$-specific time trends

$u_{i j t}$ is a random disturbance term whose expectation is zero and whose variance differs by

PMSA and which exhibits serial correlation by PMSA 
The model uses PMSA fixed-effects to control for all time-invariant characteristics that are specific to a PMSA and that contribute to rent levels. The model also uses PMSA-specific time trends created through an interaction of PMSA dummy variables and a variable indicating the time period the rental data was collected (the odd years between 1993 and 2005). The effect of the compensating differential itself is measured through the sporting variables that indicate the presence or absence of minor league baseball teams at various levels in a PMSA in a particular year.

The ordinary least squares estimation of the regression implements a process called cluster corrected standard errors. This technique accounts for the fact that variance of the error term within a cluster (PMSA-year combination) is constant but may vary across clusters. Both Carlino and Coulson (2004) and Coates et al. (2006) identified this as a necessary technique to correct the error variance in the AHS data. In addition, this dataset utilizes probability weights and therefore reports the Huber/White/sandwich robust standard errors to account for heteroskedasticity.

As noted above, there are concerns about this hedonic approach to estimating the amenity value of sports. Here we address these concerns for our analysis. The chief concern identified above is the possible correlation of the minor league variables with the regression error, perhaps because of reverse causation. In other words, perhaps minor league teams simply move to cities that are growing or that have higher rents. In this case, causation may run from growing population and higher rents to presence of a team, rather than the other way around. Indeed, minor league teams move much more frequently than major league teams (see Table 1). While we have no exogenous instrument to determine where minor league teams will locate, we have considerable evidence that this issue is not a problem. 
Agha (2013) reports that minor league teams, like their major league counterparts, are most often lured to cities where the political environment offers the best stadium deal, not to cities that have higher rents. Bellamy and Whitson (2009) also discuss Canadian teams that moved to mostly smaller cities in the U.S. that "aggressively sought out the teams...[and] subsidized playing facilities" (p. 93).

Second, and perhaps most importantly, there is no evidence that minor league clubs are placed in growing markets. We split our sample into quartiles by population size. Over our sample, 14 cities either rose out of the bottom or rose into the top quartile in terms of population. Only 3 of these 14 growing cities gained a team during the sample period; those cities growing fastest did not acquire teams. For example, Orlando, FL is one of the ten of these fast growing cities that did not gain a team. In fact, it actually started the period with two teams and lost one. One of the others, Ft. Lauderdale, FL, permanently lost its only minor league franchise. Salt Lake City, UT rose to the top quartile and acquired two clubs; Lexington, KY rose out of the bottom population quartile and had a franchise from 2001 on. Jackson, MS also acquired a club during the period, but this club merely replaced the one it had lost earlier in the sample period. The bottom line is that the evidence does not support the notion that clubs are moving to high growth areas, so we are not concerned that causation runs from rent to team presence.

A second concern expressed in the literature is that city size and team presence are highly collinear, making estimation of the effects of the sports difficult (Hamilton \& Kahn, 1997; Rappaport \& Wilkerson, 2001). Minor league baseball provides a good context to avoid this problem since city size and team presence are, in fact, uncorrelated. In 2006, minor league baseball teams were located in cities with Metropolitan Statistical Area (MSA) populations as large as 18,782,715 (New York City) and as small as 48,247 (Burlington, IA). This variability in 
population is an important characteristic of estimation and reduces some concern over the collinearity between city size and team presence of a team, and rent levels. In addition, minor league teams in the U.S. played in 303 unique metropolitan areas between 1993 and 2005 which allows a larger sample of cities to be used to measure a compensating differential effect.

At the same time, the AHS data does not include all the cities that hosted a minor league club. For example, Burlington, IA, and many other cities large and small are not in the AHS data. In fact, the smallest PMSA in the AHS to host a team is the Duluth, Minnesota-Wisconsin Metro Area, whose population was 241,451. Moreover, because cities of all sizes can be the home of a minor league team from any classification, and large cities are naturally represented by more observations in the AHS than are small cities, we have to be careful that results are not driven by the large cities in the sample. We solve this problem by presenting estimation results using three different kinds of population quartiles.

A final concern is with the AHS data. There are substantial missing values for certain variables in the data and numerous observations whose monthly rent value is implausible or problematic. For example, Coates et al. (2006), found that several observations in the Carlino and Coulson (2004) analysis had values of zero rent. When these observations were removed from the sample, the NFL coefficient became insignificant (Coates et al., 2006). According to Coates et al. (2006), values for missing variables are not randomly occurring. Units with lower rents tend to have more missing values and tend to be missing the same variables. Therefore dropping observations with missing values will impart a selectivity bias to the sample. The challenge, then, is to balance the desire to include as many explanatory variables as possible with the desire to include as many observations as possible. The approach undertaken here is similar to Coates and Gearhart (2008). 


\section{DATA AND SAMPLE}

In the mid-1980's the U.S. Office of Management and Budget (OMB) retired the use of Standard Metropolitan Statistical Areas (SMSAs) and replaced them with Consolidated and Primary MSAs (CMSAs and PMSAs). For example, the Buffalo-Niagara CMSA is composed of the Buffalo PMSA and the Niagara Falls PMSA.

The AHS has used these 1983 OMB definitions from the time it first began to the present. As OMB metro area definitions have changed the AHS has not. This provides a level of continuity in the survey, but also makes it difficult to compare it to the current OMB definition of MSAs. There are several consequences of using the 1983 definitions.

First, most metro areas now contain more counties than they did in 1983 because their geographic areas have expanded. Because the geographic area is not the same, census and other government data collected via the current OMB definition of MSAs are not comparable with the AHS data collected at the PMSA level. Thus, this research collected all data at the county level. This allows the correct counties to be conglomerated into the correct PMSA to create correct values for variables such as population, employment, and income. These county-created PMSA variables accurately reflect the geographic region that was used in the 1983 OMB definition since the AHS continues to use these 1983 definitions to obtain housing samples.

Individual housing unit data ${ }^{2}$ are available for every odd numbered year from 1993 to 2005 from the AHS national survey. The AHS PMSAs range in population size from 9.89 million (Los Angeles-Long Beach-Santa Ana, CA) to 175,471 (Beaver County, PA). Data was

${ }^{2}$ The AHS collects self-reported values of both rented and owned properties. Rents, which are commonly paid monthly, are likely more accurately self-reported than the estimated value of a home which may not have been sold for many years. For this reason, we rely on the reported rental values. 
collected on every minor league team that played between 1993 and 2005 and included 3 AAA leagues, 3 AA leagues, 7 A leagues, 2 advanced rookie leagues, and 22 independent leagues. The number of affiliated or independent minor league teams was assigned to each housing observation based on location and year. The final sample consists of individual household observations in 138 PMSAs. Twenty-one PMSAs hosted no minor league teams in the sample period, 58 had teams in all sample years, while 59 had a team in only some of the sample years. Twenty-one PMSAs hosted more than one minor league team in the sample years.

The AHS provides a weighting scheme to account for known sampling errors. Those probability weights are implemented here to provide for more representative values in each PMSA. Descriptive statistics for the variables used in the analysis are presented in Table 2. <insert Table 2 here>

As in Carlino and Coulson (2004) and Coates and Gearhart (2008), the dependent variable is the natural log of deflated monthly rent (base year 1993) paid by household $i$ in city $j$ at time $t$ as reported for individual housing units in the AHS. Monthly rent is adjusted using the consumer price index from the Bureau of Labor Statistics. Note that the minimum value of the rent variable is 20.87, which may seem an implausibly low value. Coates, et al. (2006) found Carlino and Coulson's results were highly sensitive to the inclusion of a small number of observations with rents below $\$ 20$ per month, so we too have excluded those observations.

A large number of independent variables from the AHS are used to capture the effects of the characteristics of the unit and the neighborhood on rents. Housing variables that are expected to be associated with higher rents include: central air conditioning, structure is a detached oneunit building, garage or carport is included, building has more than six floors, public sewer connection, number of bathrooms, and number of bedrooms. Housing characteristics expected to 
be associated with lower levels of rent include unit located in PMSA central city and unit has holes in floor. Similarly, the dummy variables that measure the presence of neighborhood crime, vandalism, trash, and noise will be associated with lower rents.

To the AHS variables we add information on the local economy, such as the employment rate, population growth rate, and per capita income from the previous year, and minor league baseball variables. Population growth, lagged per capita income, and the rate of employment control for local economic conditions that affect rent. All are indicators of strong economies and are expected to have positive coefficients. Because it is possible to have multiple minor league teams in the same market and for them to be either affiliated or independent, the number of minor league teams in a PMSA are counted separately by affiliated and independent status. We hypothesize that the two types of teams may have different impacts on the local economy. Compared to independent teams, affiliated teams are hypothesized to contribute to increased quality of life and therefore greater rents because they have a higher level of media exposure, stronger brands, the advantage of major league affiliations, and longer market longevity.

Interest in the impact of minor league baseball teams on local communities is driven in part by the public policy concern whether these teams provide sufficient benefits to warrant large public subsidies for stadium construction. Consequently, analysis also includes an accounting of the impact of these stadiums on rents. A count variable indicates the number of new stadiums built and, if the stadiums provide amenity benefits, they should be associated with higher rents. Of course, it is also possible that the costs of the subsidies outweigh the benefits of the facilities, in which case stadiums will be associated with lower rents. ${ }^{3}$

${ }^{3}$ We also estimated each of the models including dummy variables indicating the presence of one or more franchises from each of the NBA, NFL, NHL, and MLB. The general 
The regression models also include PMSA fixed-effects and PMSA-specific time trends. The fixed-effects control for time-invariant city-specific influences on rents such as weather and geography, proximity to water, and any political and cultural factors that cannot be otherwise addressed. The PMSA-specific time trends allow each city to be growing differently, perhaps because a PMSA is in the Sun Belt rather than the Rust Belt or because it is an attractive place for immigrants, near to a rapidly growing larger city, or for any other reasons.

\section{EMPIRICAL RESULTS}

Existing research suggests that differential effects exist between affiliated and independent teams as well as between large and small cities. Accordingly, we conduct separate regressions on subsets of the data based on city size. There are, of course, multiple methods of sorting the data based on PMSA size. We investigated three separate methods and believe the approach taken here provides a complete picture as to what would be commonly thought of as small versus large markets.

<insert Table 3>

The quartiles in Table 3 were derived using all of the observations in the dataset so that each quartile contains approximately $25 \%$ of the observations. The bottom quartile includes rental housing units in PMSAs with populations less than 1,321,255 and the top quartile includes units in PMSAs with populations greater than 6,438,968. The AHS obtains more observations from larger PMSAs and fewer from smaller PMSAs. The result is that there are only three PMSAs represented in the top quartile (Chicago, Los Angeles, and New York) while the bottom quartile contains 101 unique PMSAs.

conclusions are not affected by these additional variables, so we do not discuss or report them. Results of those models are available upon request. 
Coefficient estimates for the unit, neighborhood, and PMSA control variables vary slightly from quartile to quartile. Some commonalities exist. In each case, central air conditioning, number of bedrooms, number of bathrooms, and having a garage are always positive and statistically significant. Being in the central city or in a high rise significantly lowers rent in all size metropolitan areas. Nearby crime and abandoned buildings lower rents significantly in each classification, as does the presence of junk in the streets in the smallest and middle groups. Oddly, street noise raises rents in the largest PMSAs but has no impact on rents in the smaller PMSAs. The three PMSA characteristics variables have the least similarity across the three city size groupings. Rapid population growth lowers rents in the middle size cities but has no impact in either of the other groups. Higher income raises rents in all three groupings but at the 5\% level in only the two smaller ones. A higher employment rate raises rent only in the smallest PMSAs. All of the PMSA fixed-effects are significant at $p<0.0001$ and about half of the PMSA-specific time trends are significant at $\mathrm{p}<0.05$.

Most importantly for our purposes, the evidence is that affiliated clubs are associated with a $5.7 \%(\mathrm{p}=0.002)$ increase in rents in PMSAs in the bottom quartile of population but have no impact on either the middle two or top quartiles. Independent franchises have no impact in any of the three groupings. Affiliated stadiums have positive effects in medium sized markets but no stadium effects are found for any other size population or for independent franchises.

One challenge with using quartiles based on the total number of observations is that it is difficult to see effects in the bottom quartile where a population less that 1.3 million encompasses a very large number of PMSAs. This is made more obvious when recognizing that the median population of an affiliated market is 494,831 . Similarly, in the top quartile there are 
lots of observations, but the effects are estimated on only three PMSAs and are difficult to generalize.

To further improve the ability to investigate effects between large and small cities, a second method generates quartiles based on PMSA-year combinations. In other words, the PMSAs are divided into quartiles based purely on their annual population, not multiple observations in the same year with the same population. The lowest quartile in the analysis does not have $25 \%$ of the observations because the cities in the group have small populations and therefore very few housing units sampled by the AHS. The top quartile will have far more than $25 \%$ of the observations because the cities in that group are all very large contributors to the AHS sample. The result is that the bottom quartile includes populations less than 415,174 and the top quartile populations greater than 1,382,375. This method allows for a better view into the traditional smaller markets that host minor league teams.

<insert Table 4 here>

Whereas the results in Table 3 have population less than 1.3 million in the bottom quartile, those same populations are represented in the bottom and two middle quartiles in Table 4. This more nuanced view of population shows that the positive effect of affiliated franchises is still present, but only exists for PMSAs where the population ranges from 415,174 to 1,382,375. Affiliated teams have no significant effects on the 22 PMSAs with the smallest populations. Both affiliated and independent stadiums are associated with decreases in rent in the bottom quartile although the sample size is too small to make any generalizations. For example, only one stadium, in Corpus Christi, TX in 2003, was used to estimate the independent stadium effect. Similarly, only five stadiums were used to estimate the affiliated stadium effect. This point is addressed further in the discussion. 
Although PMSA-year quartiles allow for a better picture of what is happening in smaller cities, the number of observations is incredibly small, especially in the bottom quartile. This is indicative of the AHS methodology where there are few observations in small markets even though there are 33 unique PMSAs represented.

The second challenge with using quartiles with firm population boundaries is that some cities moved up into different quartiles over time effectively splitting the observations for a city into different quartiles. For example, Salt Lake City, UT, a market with both a AAA and a rookie team, had a 2003 population of 1,174,040 (middle quartiles), but by 2005 had a population of $1,447,832$ (top quartile). In order to measure the effect of a team on a PMSA it was necessary to develop a third method to keep all observations for a PMSA together.

To further improve the PMSA-year quartile method so that every year of a PMSA was in the same population group, PMSAs were individually coded to be in the bottom quartile only if the population was below 415,174 for every odd year from 1993 to 2005. PMSAs that spanned the bottom and middle quartiles were coded into a separate group that "rose out of the bottom." Similarly, the top quartile only included PMSAs where the population was above $1,382,375$ for every year in the sample. A PMSA that spanned the middle quartiles and top quartiles was coded into a separate group that "rose to the top." Table 5 presents these results. <insert Table 5 here>

Breaking down the sample further, as is done in Table 5, the positive impact of the affiliated franchises in the middle quartiles described in Table 4 takes on a different look. Positive and statistically significant impacts of affiliated minor league franchises occur in those cities that rose out of the bottom $(7.8 \%, \mathrm{p}=0.047)$ or rose into the top $(6.8 \%, \mathrm{p}=0.030)$. In other words, it appears possible that affiliated minor league franchises are placed in locations that are 
growing, and this growth is what is driving rents up. This finding is often interpreted as evidence that minor league teams choose to move to growing markets resulting in endogeneity of the minor league dummy variables and biased and inconsistent coefficient estimates.

Further examination makes this explanation unlikely for three distinct reasons. First, as we discussed earlier, there is no evidence that minor league teams actually move into the more rapidly growing communities. Second, population growth of the PMSA is an explanatory variable in these regressions, and is only statistically significant in the rose to the top subsample.

Third, and finally, while the minor league dummy variable is not statistically significant at $5 \%$ for cities in the middle quartiles, the coefficient is significant at $8 \%$, suggesting that the effect of minor league franchises may be spread throughout the center of the distribution of PMSAs, and not necessarily present only at the fringes of the middle.

\section{DISCUSSION}

\section{A. Teams and Stadiums}

The theory of compensating differentials suggests that people are willing to pay higher rents to live in a city with a team. The results presented here show that affiliated minor league baseball teams in mid-sized markets are a statistically significant positive amenity that are associated with increased local rents. This positive effect exists even when a market also hosts a major league team. On the other hand, independent minor league teams are associated with no change in rents in any circumstances. It is natural to wonder why such a difference exists between businesses with virtually identical products but with different strategic alliances. There are three reasons an affiliated franchise may be a valuable local amenity. 
First, although independent teams rarely receive national media attention, affiliated teams are more likely to be in the spotlight when a star player is sent down to recover from an injury. This attention helps identify a team with a city and create positive associations that can help small cities achieve some distinction. Indeed, in 1989 when the International City Management Association surveyed cities with minor league teams, city managers claimed the benefits of a team included community identity, regional prestige, and civic pride (Johnson, 1995). And despite financial losses, $82 \%$ said that maintaining the team was a priority. This is clear evidence that the intangible benefits of identity, prestige, and pride had value and were worth paying for.

Second, the limited supply of minor league teams, similar to the limited supply of major league teams, creates an excess demand from other municipalities to host a club (Siegfried \& Zimbalist, 2000). Having a club when other cities do not, and could not, creates a situation whereby the addition of an affiliated minor league team to a town may serve as a source of pride to the extent that the team is a distinct cultural amenity.

The final explanation is based on simple finances; if a fan is subject to a firm budget constraint and values the in-game experience then minor league baseball may be the only reasonable alternative to MLB and is thus a valued local attraction. Research by Gitter and Rhoads (2010) suggests minor league games are in fact a substitute for major league games. This effect may be stronger when the nearest MLB club is a long distance away. Indeed, the rose out of the bottom quartile and rose into the top quartile PMSAs for which a positive impact of a minor league affiliated club was found are, in most cases, several hours by car from the nearest MLB city. 
But why are independent franchises associated with no change in local rents? It is clear that independent teams are less financially stable, more likely to fold, and lack any association with well-known national brands. In addition, independent teams are often of lower caliber. Although the quality of play ranges from the equivalent of AAA to A and ballparks range from new multi-million dollar parks to high school fields, the majority of independent teams tend to be lower quality and play in smaller, older venues (Bouton, 2005). Thus, despite the similar onfield product, there appear to be reasonable explanations as to why affiliated teams may generate measurable non-pecuniary benefits and independent teams may not.

Similar to teams, if stadiums are an amenity that people are willing to pay for, residents will bid up rents to live where there is a new stadium. On the other hand, if the stadium costs exceed the benefits, this will show up as lower rents where stadiums have been built recently. Regardless of how city size was treated in Tables 3-5, the majority of the stadium estimates were insignificant. For those that were significant, the results were often estimated using only one or a very small number of PMSAs, and so should not be generalized. That both positive and negative significant coefficient estimates are found supports the lack of robustness and generalizability of the stadium results.

\section{B. City Size}

The two prevailing positions on the value of minor league teams to their host cities implicitly assume that minor league teams play in small cities. The position that minor league baseball has value to its host city because the team's impact is large relative to the small city, despite being small in an absolute sense, relies on teams being in small cities. Furthermore, a minor league team in a large city has little impact both because it is small absolutely and because it is very small relative to the host city. For example, a minor league team in the New York City 
metropolitan area likely will not generate much amenity for the city as it is simply too small in the scope of the city. The AHS captures these largest cities and confirms the lack of an effect in those markets, but unfortunately does a poor job of representing the small cities. The smallest city in the AHS data has a population of 175,471 , a population too large to capture the smallest minor league cities. Researchers are encouraged to find data that can test for the presence of a social value in these very small minor league cities.

An important finding of this research is the identification of an effect of minor league baseball in mid-sized cities. This finding does not fit into either position on whether and where minor league teams might generate value. There are 59 cities in the middle quartiles, but only 7 of them had a major league franchise at any time during 1993-2005. Salt Lake City, UT, Indianapolis, IN, and New Orleans, LA each had a team throughout the period, while Jacksonville, FL and Nashville, TN gained NFL franchises; Raleigh, NC and Nashville, TN gained NHL franchises; and Memphis, TN gained an NBA franchise. In other words, despite being relatively large metropolitan areas, for many of these middle quartile cities, minor league baseball was the only professional sport in town. As such, minor league baseball may take on an importance that it would not have once the cities acquire a major league franchise. And, of course, these cities seek major league franchises, as evidenced by four of them acquiring teams during the sample, and another (Oklahoma City, OK) obtaining one after the sample period.

In sum, middle quartile cities have the population and corporate infrastructure to support a minor league team and in most cases, with no other major league teams in the city, the minor league team may very well be a local amenity that allows residents to derive local pride in place. C. Policy Implications 
Since 2002, U.S. cities have spent an average of $\$ 200$ million annually to build stadiums for minor league baseball teams. Stadium proponents claim these subsidies are warranted based on future pecuniary and non-pecuniary gains to the local economy. Thus, identifying the public good nature of minor league teams and further quantifying the aggregate worth of these teams is of considerable importance to team owners, elected officials, and city managers, especially when public subsidies are justified in the form of gains to the local community.

Carlino and Coulson (2004) estimated the presence of an NFL team increased monthly rent by $8 \%$ or $\$ 480$ annually. Based on an average of 290,000 households in a typical central city they estimated the aggregate annual value to a city is $\$ 139$ million in 1993 dollars, or $\$ 216.5$ million in 2011 dollars. Applying a similar method to minor league baseball teams, our results suggest similar sized effects. For example, for the nine PMSAs in the rose out of the bottom quartile in Table 5, the average rent is $\$ 469.88$ for 168,424 households. Given a $7.79 \%$ (Table 5) rent effect for these PMSAs the aggregate gain in a PMSA is \$74 million in 1993 dollars or \$115.2 million in 2011 dollars. A similar calculation for the five PMSAs that rose to the top quartile in Table 5 finds an average rent of $\$ 501.50,546,188$ households, a rent effect of $6.79 \%$, and a PMSA gain of \$223.2 million in 1993 dollars or \$347.6 million in 2011 dollars.

As a percentage of total output, the rent effect is quite small. Direct comparisons cannot be made between 1993 definition PMSAs used in the AHS data and the current definitions of MSAs because the geographic areas are different (see Section V.). Despite that, an example from a representative city can provide a rough sense of the magnitude of the effect. Indianapolis, IN is a city in the rose to the top quartile in Table 5. The 2005 GDP is $\$ 88,665$ million or $\$ 130,777$ million in 2011 dollars. The average aggregate amenity for cities that rose to the top 
quartile is $\$ 347.6$ million (the largest of all of the significant quartiles) which is $0.2 \%$ of total output. As a percentage of total PMSA income the rent effect in Indianapolis is $0.66 \%$.

If a community is seeking to improve quality of life for the greatest number of residents at the least expense, then more research is needed on the value and cost of alternate local amenities (e.g. libraries, symphonies, good roads, or regional parks). Gyourko \& Tracy (1991) report estimates of the value of a variety of local amenities, in 1979 prices, but they did not address sport franchises or stadiums as possibilities. For example, they find that residents are willing to pay $\$ 21.84$ ( $\$ 43.47$ in 1993 dollars) for a $1 \%$ increase in sunny days, $\$ 6.36$ (\$12.66) to avoid an increase in airborne particulates, \$6.84 (\$13.61) to avoid an increase in student teacher ratios, and $\$ 1.82$ (\$3.62) for an additional hospital bed per thousand people. Their results are far smaller than Carlino and Coulson (2004) found for the NFL or than the findings here for minor league baseball. This is likely because the amenities studied by Gyourko and Tracy listed above are highly divisible and the implicit prices are for marginal changes whereas the presence of an NFL franchise or a minor league baseball team is not a marginal change. Gyourko and Tracy (1991) also find that being near the coast raises the annual rental value by $\$ 654.15$ ( $\$ 1301.76$ in 1993 dollars), a figure much more akin to those for the NFL or minor league baseball teams.

\section{CONCLUSION}

We analyzed different sized markets through a variety of different methods. The results indicate that affiliated minor league teams are associated with a 6-8\% increase in rents in midsized cities with populations ranging from 0.4 million to 1.4 million with the most significant effects at the ends of this range. The effect is not limited to growing cities or those that gained a minor league team. New stadiums are associated with negative effects on rents in small markets, 
although the sample size is limited and should not be generalized. Finally, independent teams are not significantly related to rents. These results add to the growing literature that realizes once we move beyond the 50 largest, relatively homogeneous cities hosting major league franchises that city size plays an important role in the relative effect of sports teams and events.

What is the non-pecuniary value of a sports team to a local community? There have been many attempts to answer this question using a variety of methods. While it may be difficult to quantify what might be most appropriately termed an emotional response, this research has presented evidence that affiliated minor league baseball teams in some markets are associated with gains in rent that, in a compensating differential framework, signal that residents perceive the teams to be a valuable commodity. These results address the concern of some scholars that minor league teams, in any sport, are incapable of generating positive effects because they lack the cachet of major league professional sports. Even without the glamour of national media attention, local minor league teams may provide a degree of respectability that can bring recognition to mid-sized cities that are striving to prove themselves to be "big league". This civic pride as well as the joy of seeing the local team succeed is valuable enough that consumers are willing to pay higher rents in some cities that are home to a minor league baseball team. With minor league baseball teams playing in over 200 cities in any given year, these results are applicable to a broad spectrum of urban managers throughout the U.S. 


\section{REFERENCES}

Agha, N. "The economic impact of stadia and teams: The case of Minor League Baseball." Journal of Sports Economics, 14(3), 2013, 227-252.

Agha, N. and D. A. Rascher. "An explanation of economic impact: Why positive impacts can exist for smaller sports." Sport, Business and Management: an International Journal, in press.

Ahlfeldt, G., and W. Maennig. "Impact of sports arenas on land values: Evidence from Berlin." The Annals of Regional Science, 44(2), 2010, 205-227.

Bellamy, R. \& D. Whitson. "Going South: Professional Baseball's Contraction in Canada." NINE: A Journal of Baseball History and Culture, 18(1), 2009, 86-106.

Bouton, J. Foul Ball. Guilford, Connecticut: The Lyons Press, 2005.

Carlino, G., and N. E. Coulson. "Compensating differentials and the social benefits of the NFL." Journal of Urban Economics, 56(1), 2004, 25-50.

Carlino, G., and N. E. Coulson. "Compensating differentials and the social benefit of the NFL: Reply." Journal of Urban Economics, 60(1), 2006, 132-138.

Coates, D. "Stadiums and arenas: Economic development or economic redistribution?" Contemporary Economic Policy, 25(4), 2007, 565-577.

Coates, D., \& C. A. Depken. "Mega-events: Is Baylor football to Waco what the Super Bowl is to Houston?" Journal of Sports Economics, 12(6), 2011, 599-620.

Coates, D., and D. Gearhart. "NASCAR as a public good." International Journal of Sport Finance, 3(1), 2008, 42-57.

Coates, D., and B. R. Humphreys. "Professional sports facilities, franchises and urban economic development." Public Finance and Management, 3(3), 2003, 335-357.

Coates, D., B. R. Humphreys, and A. Zimbalist "Compensating differentials and the social benefits of the NFL: A comment." Journal of Urban Economics, 60(1), 2006, 124-131.

Coates, D., and V. Matheson. "Mega-Events and Housing Costs: Raising the Rent while Raising the Roof?" The Annals of Regional Science, 46, 2011, 119-137.

Court, A. T. Hedonic price indexes with automotive examples. The dynamics of automobile demand. New York, NY: General Motors, 1939.

Dehring, C. A., C. A. Depken, and M. R. Ward. "The impact of stadium announcements on residential property values: Evidence from a natural experiment in Dallas-Fort Worth." Contemporary Economic Policy, 25(4), 2007, 627-638. 
Feng, X., and B. R. Humphreys. "The Impact of Professional Sports Facilities on Housing Values: Evidence from Census Block Group Data.” City, Culture \& Society, 3(3), 2012, 189-200.

Foster, W. M., and C. Hyatt. "I despise them! I detest them! Franchise relocation and the expanded model of organizational identification." Journal of Sport Management, 21(2), 2007, 194-212.

Gitter, S. R., and T. A. Rhoads. "Determinants of minor league baseball attendance." Journal of Sports Economics, 11(6), 2010, 614-628.

Griliches, Z. Hedonic price indexes for automobiles: An econometric analysis of quality change. The Price Statistics of the Federal Government, General Series no. 73, 1961.

Griliches, Z. Price indexes and quality change: Studies in new methods of measurement. Cambridge, MA: Harvard University Press, 1971.

Gyourko, J., and J. Tracy. "The structure of local public finance and the quality of life." Journal of Political Economy, 99(4), 1991, 774-806.

Hamilton, B. W., and P. Kahn. "Baltimore's Camden Yards ballparks," in Sports, jobs, and taxes: The economic impact of sport teams and stadiums edited by R. Noll and A.

Zimbalist. Washington, DC: Brookings Institution, 1997, 245-281.

Johnson, A. T. Minor league baseball and local economic development. Urbana and Chicago, IL: University of Illinois Press, 1995.

Johnson, A. T., and A. Sack. "Assessing the value of sports facilities: The importance of noneconomic factors.” Economic Development Quarterly, 10(4), 1996, 369-381.

Johnson, B. K., P. A. Groothuis, and J. C. Whitehead. "The value of public goods generated by a major league sports team: The CVM approach.” Journal of Sports Economics, 2(1), 2001, 6-21.

Johnson, B. K., M. J. Mondello, and J. C. Whitehead. "The value of public goods generated by a National Football League team.” Journal of Sport Management, 21(1), 2007, 123-136.

Johnson, B. K., and J. C. Whitehead. "Value of public goods from sports stadiums: The CVM approach." Contemporary Economic Policy, 18(1), 2000, 48.

Kraus, R. S. Minor league baseball: Community building through hometown sports. Binghamton, NY: Haworth Press, 2003.

Matheson, V. A. "Is smaller better? A comment on "Comparative Economic Impact Analyses" by Michael Mondello and Patrick Rishe.” Economic Development Quarterly, 20(2), 2006, 192-195. 
Noll, R. G., and A. Zimbalist. "The economic impact of sports teams and facilities," in Sports, jobs, and taxes: The economic impact of sport teams and stadiums edited by R. Noll and A. Zimbalist. Washington, DC: Brookings Institution, 1997, 55-91.

Okner, B. A. "Subsidies of stadiums and arenas," in Government and the sports business edited by R. Noll. Washington, DC: Brookings Institution, 1974.

Rappaport, J., and C. Wilkerson. "What are the benefits of hosting a major league sports franchise?” Economic Review-Federal Reserve Bank of Kansas City, 86(1), 2001, 55-86.

Roback, J. "Wages, rents, and the quality of life." Journal of Political Economy, 90(6), 1982, 1257-1278.

Rosen, S. "Hedonic prices and implicit markets: Product differentiation in pure competition." Journal of Political Economy, 82(1), 1974, 34-55.

Rosentraub, M. S., and D. Swindell. ""Just say no?" The economic and political realities of a small city's investment in minor league baseball." Economic Development Quarterly, 5(2), 1991, 152-67.

Rosentraub, M. S., D. Swindell, and S. Tzvetkova. "Public dollars, sport facilities, and intangible benefits: The value of a team to a region's residents and tourists." Journal of Tourism, 9(2), 2008, 133-159.

Roy, D. P. "Impact of new minor league baseball stadiums on game attendance." Sport Marketing Quarterly, 17, 2008, 146-153.

Seaman, B. "The Supply Constraint Problem in Economic Impact Analysis: An Arts/Sports Disparity." Paper presented at Lasting Effects: Assessing the Future of Economic Impact Analysis of the Arts Conference, Tarrytown, NY, 2004.

Siegfried, J., and A. Zimbalist. "The economics of sports facilities and their communities." The Journal of Economic Perspectives, 14(3), 2000, 95-114.

Swindell, D., and M. S. Rosentraub. "Who benefits from the presence of professional sports teams? The implications for public funding of stadiums and arenas." Public Administration Review, 58(1), 1998, 11-20.

Tu, C. C. "How does a new sports stadium affect housing values? The case of FedEx field." Land Economics, 81(3), 2005, 379-395.

Winfree, J. A. "Ownership structure between Major and Minor League Baseball." European Sport Management Quarterly, 5(4), 2005, 343-356.

Zimmerman, D. "Subsidizing stadiums: Who benefits, who pays?" in Sports, jobs, and taxes: The economic impact of sport teams and stadiums edited by R. Noll and A. Zimbalist. Washington, DC: Brookings Institution, 1997, 199-145. 


\title{
ABBREVIATIONS
}

\author{
AHS: American Housing Survey \\ CMSA: Consolidated Metropolitan Statistical Area \\ MLB: Major League Baseball \\ MSA: Metropolitan Statistical Area \\ NBA: National Basketball Association \\ NFL: National Football League \\ NHL: National Hockey League \\ PMSA: Primary Metropolitan Statistical Area \\ OMB: Office of Management and Budget \\ SMSA: Standard Metropolitan Statistical Area
}


FIGURE 1

Number of Teams and Annual Attendance, 2011

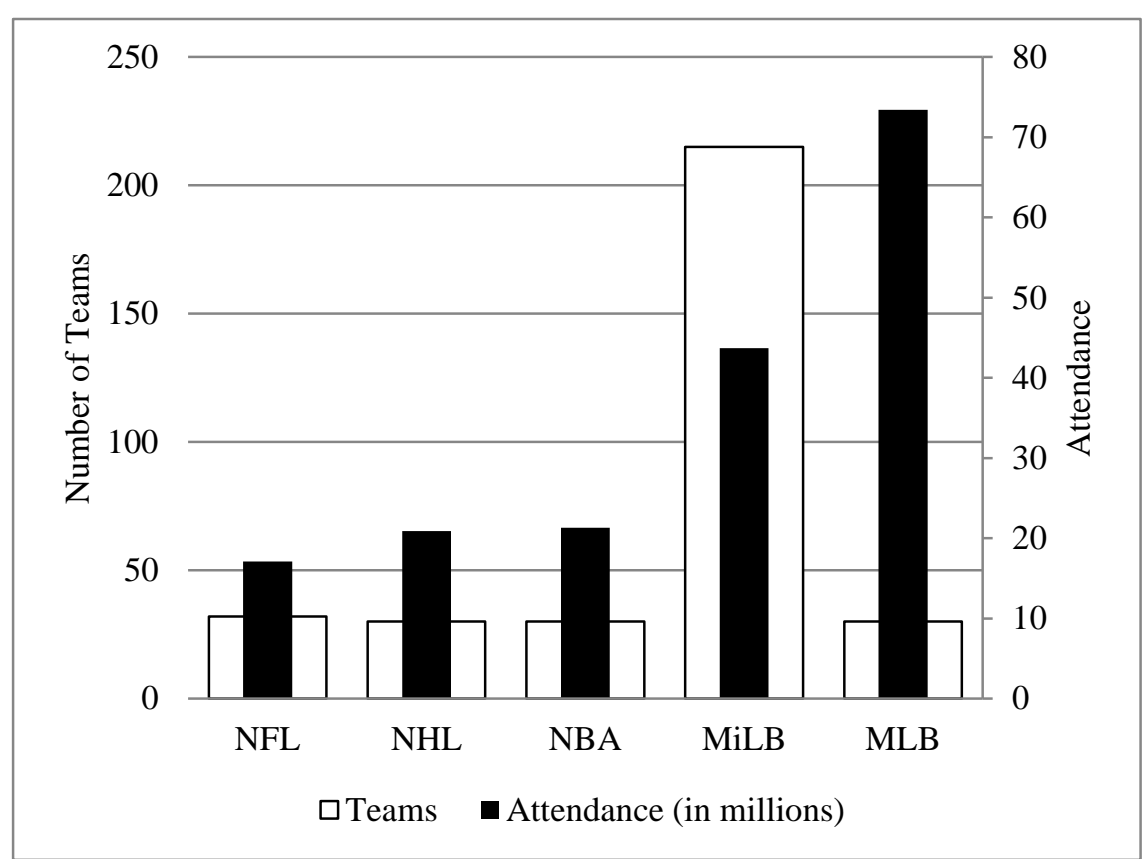




\section{TABLE 1}

Characteristics of Minor League Metropolitan Statistical Areas (MSAs) in 2006, by Classsification

\begin{tabular}{|c|c|c|c|c|c|c|c|}
\hline League (n) & $\begin{array}{c}\text { Median } \\
\text { MSA } \\
\text { Population } \\
\end{array}$ & $\begin{array}{c}\text { Minimum } \\
\text { MSA } \\
\text { Population } \\
\end{array}$ & $\begin{array}{l}\text { Maximum } \\
\text { MSA } \\
\text { Population } \\
\end{array}$ & $\begin{array}{c}\text { Average } \\
\text { Stadium Seating } \\
\text { Capacity } \\
\end{array}$ & $\begin{array}{c}\text { Average Games } \\
\text { Played Per } \\
\text { Season } \\
\end{array}$ & $\begin{array}{c}\text { Average } \\
\text { years in an } \\
\text { MSA } \\
\end{array}$ & $\begin{array}{c}\text { \% Playing in MSA } \\
\text { with any Major } \\
\text { League Team }\end{array}$ \\
\hline MLB (29) & $4,164,463$ & $1,540,525$ & $18,782,715$ & 44,774 & 161 & 24.1 & $100 \%$ \\
\hline All Affiliated (144) & 494,831 & 48,247 & $18,782,715$ & 7,288 & 118 & 16.1 & $17 \%$ \\
\hline AAA (29) & $1,175,937$ & 469,196 & $3,262,445$ & 12,773 & 143 & 17.2 & $38 \%$ \\
\hline AA (28) & 461,502 & 81,655 & $5,982,787$ & 7,519 & 140 & 13.6 & $11 \%$ \\
\hline$A+(20)$ & 519,414 & 57,079 & $5,810,834$ & 5,784 & 138 & 18.8 & $20 \%$ \\
\hline A (30) & 371,571 & 48,247 & $18,782,715$ & 5,849 & 138 & 15.6 & $13 \%$ \\
\hline A- $(21)$ & 379,862 & 58,418 & $18,782,715$ & 4,799 & 75 & 15.1 & $24 \%$ \\
\hline Rookie (16) & 110,850 & 65,437 & 503,820 & 3,382 & 72 & 16.9 & $0 \%$ \\
\hline Ind (42) & 426,718 & 75,155 & $18,782,715$ & 4,995 & na & 4.6 & $33 \%$ \\
\hline
\end{tabular}

Notes: Because some A, A-, and Independent teams are located in metropolitan areas with MSA populations over 18 million the median values reported here are more representative of the actual market size in each classification than the average is. This table presents MSA population data and not PMSA population data. MLB figures do not include Toronto. 
TABLE 2

Descriptive Statistics, N=54825

\begin{tabular}{lrrrr}
\hline Variable & Mean & Std. Dev. & Min & Max \\
\hline Dependent Variable & & & & \\
Deflated rent (1993) & 548.40 & 292.78 & 20.87 & 2069.63 \\
Unit Dummies & & & & \\
Central air conditioning & 0.3777 & 0.484819 & 0 & 1 \\
Unit located in MSA central city & 0.6230 & 0.484630 & 0 & 1 \\
Detached one-unit building & 0.1593 & 0.365952 & 0 & 1 \\
Garage or carport included & 0.3117 & 0.463209 & 0 & 1 \\
Building has more than six floors & 0.0650 & 0.246515 & 0 & 1 \\
Unit has holes in floor & 0.0197 & 0.138807 & 0 & 1 \\
Building has less than four floors & 0.7873 & 0.409247 & 0 & 1 \\
Public sewer connection & 0.9843 & 0.124500 & 0 & 1 \\
Unit Variables & & & & \\
Number of bedrooms & 1.8035 & 0.910720 & 0 & 10 \\
Number of full and half bathrooms & 1.2169 & 0.470182 & 0 & 10.5 \\
Neighborhood Dummies & & & & \\
Crime in neighborhood & 0.2260 & 0.418248 & 0 & 1 \\
Abandoned/vandalized buildings within $1 / 2$ block & 0.0794 & 0.270353 & 0 & 1 \\
Trash or junk within 1/2 block & 0.2222 & 0.415727 & 0 & 1 \\
Noise or traffic in neighborhood & 0.2963 & 0.456622 & 0 & 1 \\
PMSA Variables & & & & \\
Population growth rate over period & 0.0106 & 0.009815 & -0.02105 & 0.06569 \\
PMSA per capita income lagged & 25576.34 & 5117.41 & 10504 & 50814 \\
PMSA rate of employment & 0.5914 & 0.068590 & 0.33346 & 0.82527 \\
Team Variables & & & & \\
Number of affiliated franchises & 0.6053 & 0.849924 & 0 & 5 \\
Number of independent franchises & 0.2217 & 0.511000 & 0 & 2 \\
Stadium Variables & & & & \\
Number of new affiliated stadiums & 0.0546 & 0.276835 & 0 & 2 \\
Number of new independent stadiums & 0.0306 & 0.230479 & 0 & 2 \\
\hline & & & & 0 \\
\hline
\end{tabular}




\section{TABLE 3}

Effects of the Presence of Minor League Baseball Teams on Rent, 1993-2005, Using Observation-based Quartiles

\begin{tabular}{|c|c|c|c|c|}
\hline & \multicolumn{3}{|c|}{ Quartiles defined by all observations } \\
\hline & & $\begin{array}{l}\text { Bottom Quartile } \\
\text { pop }<1,321,255\end{array}$ & $\begin{array}{c}\text { Middle } \\
\text { Quartiles }\end{array}$ & $\begin{array}{c}\text { Top Quartile } \\
\text { pop > 6,438,968 }\end{array}$ \\
\hline \multicolumn{2}{|l|}{ Central air conditioning } & $* * * 0.2114$ & $* * * 0.2071$ & $* * * 0.1617$ \\
\hline \multicolumn{2}{|c|}{ Unit located in MSA central city } & $* * *-0.0581$ & $* * *-0.0643$ & $*_{-} 0.0250$ \\
\hline \multicolumn{2}{|c|}{ Detached one-unit building } & -0.0046 & $* 0.0215$ & $* 0.0417$ \\
\hline \multicolumn{2}{|c|}{ Garage or carport included } & $* * * 0.1114$ & $* * * 0.1299$ & $* * * 0.1369$ \\
\hline \multicolumn{2}{|c|}{ Building has more than six floors } & $* * *_{-} 0.1122$ & $* * *-0.0907$ & $*_{-}-0.0536$ \\
\hline \multicolumn{2}{|l|}{ Unit has holes in floor } & -0.0307 & -0.0187 & $* *-0.1173$ \\
\hline \multicolumn{2}{|c|}{ Building has less than four floors } & -0.0201 & $* * *-0.0540$ & 0.0334 \\
\hline \multicolumn{2}{|l|}{ Public sewer connection } & -0.0098 & $* * 0.0656$ & -0.0635 \\
\hline \multicolumn{2}{|l|}{ Bedrooms } & $* * * 0.0799$ & $* * * 0.0797$ & $* * 0.0454$ \\
\hline \multicolumn{2}{|l|}{ Full and half baths } & $* * * 0.2105$ & $* * * 0.2048$ & $* * * 0.2059$ \\
\hline \multicolumn{2}{|l|}{ Crime in neighborhood } & $* * *-0.0380$ & $* * *-0.0437$ & $* * *_{-} 0.0842$ \\
\hline \multicolumn{2}{|l|}{ Vandalized buildings } & $* *-0.0569$ & $* * *-0.1307$ & $* * *-0.1653$ \\
\hline \multicolumn{2}{|l|}{ Trash or junk } & $* * *-0.0730$ & -0.0909 & -0.0298 \\
\hline \multicolumn{2}{|l|}{ Noise or traffic } & -0.0158 & 0.0051 & $* * * 0.0493$ \\
\hline \multicolumn{2}{|l|}{ Population growth rate } & -1.2151 & $* *-2.3049$ & -4.4749 \\
\hline \multicolumn{2}{|l|}{ Per capita income lagged } & $* 0.00001$ & $* * * 0.00002$ & 0.00002 \\
\hline \multicolumn{2}{|l|}{ Rate of employment } & $* * 0.8206$ & -0.1206 & -1.5460 \\
\hline \multirow{2}{*}{\multicolumn{2}{|c|}{ Affiliated franchises }} & $* * 0.0574(71)$ & $-0.0174(22)$ & $0.0181(2)$ \\
\hline & $\mathrm{p}$-values & 0.0020 & 0.3697 & 0.7102 \\
\hline \multirow[t]{2}{*}{ Ind. franchises } & & $0.0078(30)$ & $0.0035(15)$ & $0.0358(3)$ \\
\hline & $\mathrm{p}$-values & 0.6418 & 0.7138 & 0.1071 \\
\hline \multirow[t]{2}{*}{ Affiliated stadiums } & & $-0.0045(20)$ & $* * 0.0449(4)$ & $-0.0265(1)$ \\
\hline & p-values & 0.7916 & 0.0040 & 0.2743 \\
\hline \multirow[t]{2}{*}{ Ind. stadiums } & & $-0.0458(4)$ & $0.0299(3)$ & $0.0073(1)$ \\
\hline & p-values & 0.3791 & 0.2675 & 0.6140 \\
\hline \multicolumn{2}{|l|}{$\mathrm{R}^{2}$} & 0.3521 & 0.3480 & 0.1186 \\
\hline \multicolumn{2}{|l|}{ Observations } & 13200 & 27013 & 14612 \\
\hline \multicolumn{2}{|l|}{ Unique PMSAs } & 101 & 39 & 3 \\
\hline
\end{tabular}

Notes: The values in parenthesis after each coefficient are the number of PMSAs that were used to estimate the effect. The PMSAs in each column do not sum to the total unique PMSAs because a single PMSA may have hosted an affiliated and an independent team, for example. Similarly, the unique PMSAs are greater than 138 because some PMSAs were present in more than one quartile. PMSA fixed-effects and PMSA-specific time trends have been suppressed.

* Significant at $5 \% ; * *$ significant at $1 \% ; * * *$ significant at $0.1 \%$ 


\section{Table 4}

\section{Effects of the Presence of Minor League Baseball Teams on Rent, 1993-2005, Using PMSA-Year-based Quartiles}

\begin{tabular}{crrr}
\hline & \multicolumn{2}{c}{ Quartiles defined by single PMSA-year observations } \\
\cline { 2 - 4 } & Bottom Quartile & Middle & \multicolumn{1}{c}{ Top Quartile } \\
& pop $<415,174$ & Quartiles & pop $>1,382,375$ \\
\hline p-values & $0.0698(22)$ & $* * \mathbf{0 . 0 6 2 4 ( 5 9 )}$ & $-0.0092(21)$ \\
Affiliated franchises & 0.1768 & $\mathbf{0 . 0 0 1 9}$ & 0.7417 \\
p-values & $0.0231(11)$ & $0.0112(19)$ & $0.0243(18)$ \\
Ind. franchises & 0.3367 & 0.5899 & 0.0929 \\
Affiliated stadiums & $* * \mathbf{0 . 2 1 6 8 ( 5 )}$ & $0.0048(15)$ & $-0.0204(5)$ \\
p-values & $\mathbf{0 . 0 0 6 5}$ & 0.7729 & 0.1094 \\
Ind. stadiums & $* * * \mathbf{0 . 3 4 4 9 ( 1 )}$ & $0.0172(3)$ & $0.0050(4)$ \\
p-values & $\mathbf{0 . 0 0 0 1}$ & 0.5348 & 0.6438 \\
$\mathrm{R}^{2}$ & & & 0.2747 \\
Observations & 0.4589 & 0.3375 & 40948 \\
Unique PMSAs & 1652 & 12225 & 41 \\
\hline
\end{tabular}

Notes: The values in parenthesis after each coefficient are the number of PMSAs that were used to estimate the effect. The PMSAs in each column do not sum to the total unique PMSAs because a single PMSA may have hosted an affiliated and an independent team, for example. Similarly, the unique PMSAs are greater than 138 because some PMSAs were present in more than one quartile. PMSA fixed-effects and PMSA-specific time trends have been suppressed.

$*$ Significant at 5\%; ** significant at $1 \%$; *** significant at $0.1 \%$ 


\section{Table 5}

Effects of the Presence of Minor League Baseball Teams on Rent, 1993-2005, with PMSAs that do not Span Quartiles

\begin{tabular}{|c|c|c|c|c|c|}
\hline & \multicolumn{5}{|c|}{ Quartiles defined by single PMSA-year observations } \\
\hline & $\begin{array}{c}\text { Bottom Quartile } \\
\text { pop }<415,174\end{array}$ & $\begin{array}{l}\text { Rose out of } \\
\text { the Bottom }\end{array}$ & $\begin{array}{c}\text { Middle } \\
\text { Quartiles }\end{array}$ & $\begin{array}{l}\text { Rose to } \\
\text { the Top }\end{array}$ & $\begin{array}{c}\text { Top Quartile } \\
\text { pop > } 1,382,375\end{array}$ \\
\hline Affiliated franchises & $0.0246(13)$ & *0.0779 (9) & $0.0375(46)$ & $* 0.0679(5)$ & $-0.0083(18)$ \\
\hline p-values & 0.6164 & 0.0470 & 0.0815 & 0.0296 & 0.7686 \\
\hline Ind. franchises & $0.0156(11)$ & $-0.0223(4)$ & $0.0073(15)$ & & $0.0246(18)$ \\
\hline p-values & 0.5436 & 0.3847 & 0.7366 & & 0.0909 \\
\hline Affiliated stadiums & $* * * 0.3247(3)$ & $0.0259(3)$ & $-0.0049(13)$ & $0.0705(1)$ & $-0.0207(5)$ \\
\hline p-values & 0.0011 & 0.5671 & 0.7674 & 0.0554 & 0.1056 \\
\hline Ind. stadiums & $* * *-0.4113(1)$ & & $0.0191(3)$ & & $0.0048(4)$ \\
\hline p-values & 0.0001 & & 0.4962 & & 0.6575 \\
\hline $\mathrm{R}^{2}$ & 0.4908 & 0.4155 & 0.3305 & 0.3037 & 0.2740 \\
\hline Observations & 1299 & 848 & 10599 & 2403 & 39676 \\
\hline Unique PMSAs & 23 & 11 & 63 & 6 & 35 \\
\hline
\end{tabular}

Notes: The values in parenthesis after each coefficient are the number of PMSAs that were used to estimate the effect. The bottom quartile represents PMSAs whose population was less than 415,174 for every odd year from 1993-2005. Similarly the middle quartiles are all PMSAs where the population is fully between 415,174 and $1,382,375$ and the top quartile fully above 1,382,375. Rose out of the Bottom represents those PMSAs whose population started in the first quartile and ended in the middle quartiles. Rose to the top represents those PMSAs whose population began in the middle quartiles and finished in the top quartile. PMSA fixed-effects and PMSAspecific time trends have been suppressed.

* Significant at 5\%; ** significant at $1 \%$; *** significant at $0.1 \%$ 